\title{
Integration of a laterally acquired gene into a cell network important for growth in a strain of Vibrio rotiferianus
}

\author{
Maurizio Labbate ${ }^{1}$, Yan Boucher ${ }^{2}$, Piklu Roy Chowdhury ${ }^{1}$ and Hatch W Stokes ${ }^{1 *}$
}

\begin{abstract}
Background: Lateral Gene Transfer (LGT) is a major contributor to bacterial evolution and up to $25 \%$ of a bacterium's genome may have been acquired by this process over evolutionary periods of time. Successful LGT requires both the physical transfer of DNA and its successful incorporation into the host cell. One system that contributes to this latter step by site-specific recombination is the integron. Integrons are found in many diverse bacterial Genera and is a genetic system ubiquitous in vibrios that captures mobile DNA at a dedicated site. The presence of integron-associated genes, contained within units of mobile DNA called gene cassettes makes up a substantial component of the vibrio genome (1-3\%). Little is known about the role of this system since the vast majority of genes in vibrio arrays are highly novel and functions cannot be ascribed. It is generally regarded that strain-specific mobile genes cannot be readily integrated into the cellular machinery since any perturbation of core metabolism is likely to result in a loss of fitness.

Results: In this study, at least one mobile gene contained within the Vibrio rotiferianus strain DAT722, but lacking close relatives elsewhere, is shown to greatly reduce host fitness when deleted and tested in growth assays. The precise role of the mobile gene product is unknown but impacts on the regulation of outermembrane porins. This demonstrates that strain specific laterally acquired mobile DNA can be integrated rapidly into bacterial networks such that it becomes advantageous for survival and adaptation in changing environments.

Conclusions: Mobile genes that are highly strain specific are generally believed to act in isolation. This is because perturbation of existing cell machinery by the acquisition of a new gene by LGT is highly likely to lower fitness. In contrast, we show here that at least one mobile gene, apparently unique to a strain, encodes a product that has integrated into central cellular metabolic processes such that it greatly lowers fitness when lost under those conditions likely to be commonly encountered for the free living cell. This has ramifications for our understanding of the role mobile gene encoded products play in the cell from a systems biology perspective.
\end{abstract}

\section{Background}

The integron includes a site-specific recombination system that integrates and expresses genes present on mobile elements called gene cassettes [1]. The integron platform is defined by three characteristics: an integrase gene (intI) whose product encodes a site-specific integrase, IntI, an attachment site (attI) at which point DNA sequences are inserted and a promoter $\left(\mathrm{P}_{c}\right)$ which expresses genes within the gene cassettes inserted at attI

\footnotetext{
* Correspondence: hatch.stokes@uts.edu.au

'The ithree institute, University of Technology, Sydney. Harris Street and Broadway, Sydney, NSW 2007, Australia

Full list of author information is available at the end of the article
}

[2]. Gene cassettes can be inserted into the integron as individual units but multiple events can lead to large tandem arrays. Integrons are best known for their role in the spread of antibiotic resistance genes in clinical environments [3]. These clinical integrons harbour 1-6 gene cassettes and are often associated with mobile elements such as resistance plasmids and transposons [3]. However, integrons are diverse genetic elements found in approximately $10 \%$ of environmental bacteria [2]. In these bacteria, integrons are found in chromosomal locations and rarely carry antibiotic resistance gene cassettes indicating a general role in evolution. 
Vibrio is a genus of highly adaptable bacteria found in diverse marine-associated niches [4]. This adaptability is partly driven by lateral gene transfer (LGT), a process believed to be particularly important in this genus since the recent finding that Vibrio cholerae and other vibrios naturally take up DNA from the environment [5,6]. In the vibrio, integron cassette arrays can comprise well in excess of 100 cassettes [7]. Thus, the integron is a significant source of laterally acquired DNA in vibrio consisting of $1-3 \%$ of the total genome and generates genetic diversity even among closely related strains [2]. For example, it is the only identified genomic region that differs between some strains responsible for the current $V$. cholerae pandemic [8]. It has also been recently suggested that integron associated gene pools in the vibrios are important in adaptation to local environmental and ecological conditions [9].

Recent additional studies have provided new insight into the biology of vibrio integrons. The SOS stress response induces transcription of the integron-integrase increasing the rate of insertion, excision and shuffling of gene cassettes [10]. Furthermore, the majority of gene cassettes in a 116-cassette array [11] located in the Vibrio rotiferianus strain DAT722 [12] were found to be transcribed due to the presence of promoters distributed throughout the array [13]. Thus, cassette transcription is not absolutely dependent on being near $\mathrm{P}_{\mathrm{c}}$. Collectively these findings suggest the integron provides a more prominent role in vibrio adaptation than previously thought.

Approximately $75 \%$ of integron associated gene cassette products in Vibrio species are novel with the remainder being designated with a putative function based on the presence of known domains through in silico analysis [2] or, to a very limited extent, by protein structural analysis [14]. The novelty of gene cassette products has made them difficult targets to study. However, like most mobile DNA, gene cassettes are believed to provide their host with accessory phenotypes imparting a niche-specific advantage. The exemplar of this phenomenon is antibiotic resistance, where most of the genes driving resistance adaptation are highly mobile [15]. This has also been supported by the handful of novel gene cassettes that have been characterised proving them to be functional and include genes potentially involved in pathogenesis in $V$. cholerae [14,16-18]. It is easy to understand how a protein carrying out a single biochemical reaction, for example the chemical inactivation of an antibiotic, can act in isolation and confer a strong selective advantage when the containing cell is in an environment where a toxic compound is present. This argument can also be extended to self contained sets of genes (operons) that encode pathways conferring resistance to such things as mercury and chromate which have also been captured and spread by mobilizing elements. It is largely believed that highly mobile genes would be confined to such function-types since laterally acquired genes that influence core metabolic functions are likely to lower fitness when first captured [19]. However we show here that at least one of eight novel cassettes associated with a vibrio integron encodes a product that is integrated into cell membrane porin regulation such that its loss would impact on cell fitness under physiological conditions that would normally be encountered by the free living host.

\section{Results}

\section{Deletion of cassettes reduces growth on some carbon} sources

To investigate how cassette genes may influence adaptation in their bacterial host, deletions of cassettes were created in the integron cassette array of Vibrio rotiferianus DAT722. Two cassette deletion mutants within the 116-gene cassette array of Vibrio rotiferianus DAT722 were created (See Methods and Figure 1). These mutants removed cassettes 8-60 (designated $\mathrm{d} 8-60 \mathrm{a}$ ) in one case and cassettes 16-60 (d16-60) in the other. The ability of these mutants to grow in various media were tested and compared to the wild type parent (Figure 2). It was found that both mutants were able to grow normally in a complete medium (LB20) albeit with a slightly extended lag phase for d8-60a (Figure 2A). The two mutants were also examined for growth in marine minimal medium (2M salts, a medium that mimics marine seawater [20]) with glucose (Figure 2B) or pyruvate (Figure 2C) as a sole carbon source. The growth of both mutants was normal compared to wild type (Vibrio rotiferianus DAT722) in $2 \mathrm{M}+$ glucose as was also the case for d16-60 in pyruvate. In contrast, d8-60a grew very poorly with pyruvate as sole carbon source. Growth of this mutant however could be restored on pyruvate with the addition of glycine-betaine, a known osmoprotectant (Figure 3). Glucose is also known to be a better osmoprotectant than pyruvate and we therefore tentatively conclude that the poor growth of $\mathrm{d} 8-60 \mathrm{a}$ in pyruvate is a result of intolerance to osmotic changes and not a failure to extract carbon from this molecule. Further growth experiments supported this hypothesis with growth on other carbon sources that osmoprotect (eg trehalose) compared to failure to grow on other nonosmoprotectants (aspartic acid, glutamic acid, succinate and fumarate) (data not shown). These data suggested that this cassette array may include encoded proteins that integrate into and influence cellular processes more broadly in contrast to possessing proteins involved in single step secondary metabolism. Specifically, in DAT722, at least one cassette product appears to influence normal growth under nutrient conditions 


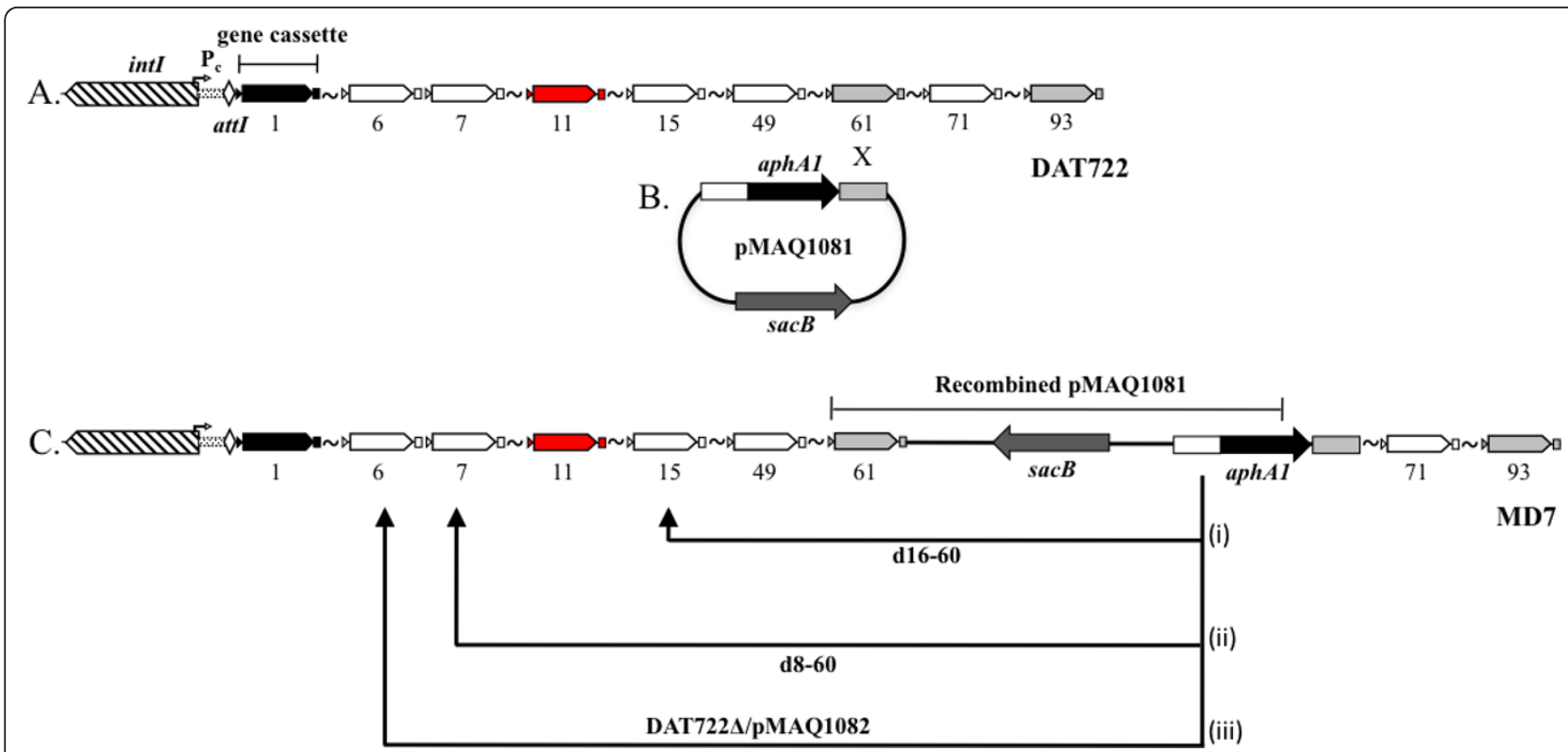

Figure 1 Creation of deletions in cassette array of Vibrio rotiferianus DAT722. Genetic features of the integron are labelled in the figure (A). The numbers below each cassette indicates its position in the array relative to attl. The white (group 1) and grey cassettes (group 2) indicate the two groups of paralogous cassettes described in the Materials and Methods section. Not all cassettes are shown with gaps of missing cassettes marked with a symbol. A 1834 bp DNA fragment consisting of, in order, a portion of the white paralogous cassette sequence (448 bp), the aphA1 gene from pLOW2 (964 bp) and a portion of the grey paralogous sequence (410 bp) was cloned into the suicide vector pCVD442 to create PMAQ1081 (B). Plasmid pMAQ1081 was conjugated into Vibrio sp. DAT722-Sm resulting in a single crossover at cassette 61 creating strain MD7 (C). Counterselection of MD7 with sucrose medium resulted in isolation of deletion mutants that had undergone a second crossover with cassette 15, creating mutant d16-60 and deletion of cassettes 16 to $60(C$, i), with cassette 7 resulting in mutants d8-60a, d8-60b and d8-60c and deletion of cassettes 8 to 60 (C, ii).

analogous to those found in seawater, the natural freeliving environment for Vibrio rotiferianus.

To confirm that the dramatic reduction in fitness of d8-60a was a result of the loss of a mobile cassette and not the consequence of a spontaneous mutation elsewhere in the genome of the isolate selected for analysis, two other independent mutants, d8-60b and d8-60c, comprising loss of the same cassettes were constructed and examined for their growth characteristics. The results for these two mutants showed significant growth impairment in minimal medium although not in a manner identical to d8-60a. In glucose, both $\mathrm{d} 8-60 \mathrm{~b}$ and $\mathrm{d} 8$ 60c had significant lag phases of up to 14 hours compared to wild type DAT722 and d8-60a but thereafter grew to achieve wild type cell densities at 24 hours (Figure $2 \mathrm{~B}$ ). In pyruvate, $\mathrm{d} 8-60 \mathrm{~b}$ and $\mathrm{d} 8-60 \mathrm{c}$ showed reduced growth rates compared to DAT722 although they were significantly better than d8-60a (Figure 2C).

All three d8-60 mutants generated a minority of microcolonies when streaked on LB20 complete medium (Figure 4). This suggested that the mutants had an overall reduced fitness that was strongly selective for mutants that compensated for loss of a function encoded within the region deleted. The nature of these compensating mutations may thus explain the variability of growth seen between mutants in minimal medium. In support of the notion that compensating mutations were being selected out was the observation that cells recovered from microcolonies that showed enhanced growth showed wild type equivalent growth in minimal medium + glucose. This is shown in cell lines d8-60b-S and d8-60c-S in Figure 2D. Taking these data together we suggest that an integron associated cassette product participates in some aspect of cell metabolism that directly or indirectly impacts on growth such that a secondary mutation(s) is required to maintain viability or growth. This product must be encoded by one of the genes located in cassettes 8 to 15 inclusive since the smaller deletion encompassing cassettes 16-60 does not display any of these effects (Figure 2).

\section{Cassette deletions change the outermembrane protein profiles of cells}

Porins play a major role in controlling the permeability of the outermembrane of Gram-negative bacteria. Changes in porin composition affect the cell's osmotic balance and nutrient transport [21]. Therefore, it was hypothesized that the likely osmotic shock of d8-60a in $2 \mathrm{M}+$ pyruvate and the growth defects of $\mathrm{d} 8-60 \mathrm{~b}$ and d8-60c in $2 \mathrm{M}+$ glucose might be due to changes in the 

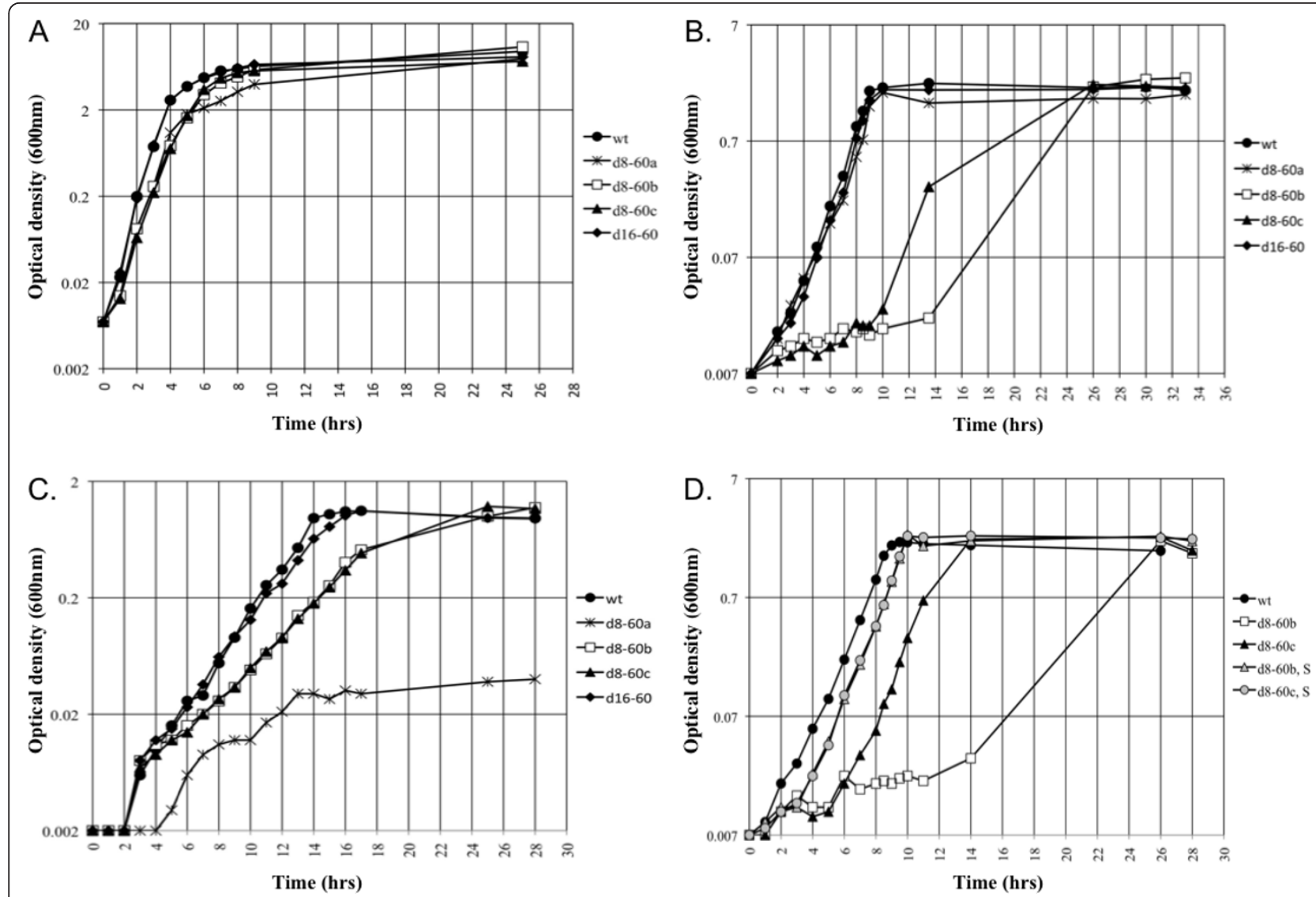

Figure 2 Growth curves of $V$. rotiferianus DAT722-Sm (wt), d8-60 (d8-60a and d8-60b, d8-60c) and d16-60 deletion mutants in LB20 (A), $2 \mathrm{M}+$ glucose (B) and $2 \mathrm{M}+$ pyruvate (C). Growth curves of the spontaneous mutants d8-60b-S and d8-60c-S in $2 \mathrm{M}+$ glucose (D). Data presented are representative of results obtained in at least three independent experiments.

composition of outermembrane porins. Outermembrane protein profiles showed significant changes in the composition of porins in all three d8-60 mutants compared to the wild-type using different growth media indicating an inability of these mutants to regulate their porins normally (Figure 5A, B and 5C). In $2 \mathrm{M}+$ glucose conditions, d8-60a showed slight decreases in four proteins identified as VapA (the structural subunit of a twodimensional lattice in the outer membrane called the Slayer; band 1), maltoporin (band 2), OmpU porin (band 3) and an OmpU-like porin (band 4) compared to the wild-type, consistent with the healthy growth of d8-60a in this medium (Figure 5A). However, the changes in regulation of porins in $\mathrm{d} 8-60 \mathrm{a}$ was clearly observed when grown in $2 \mathrm{M}+\mathrm{LB}$ nutrients as it showed increased amounts of VapA (band 1) and maltoporin (band 2) and the presence of a putative porin (band 4) not detected in the wild-type under these nutrient conditions (Figure 5C). This irregular regulation explained the inability for $\mathrm{d} 8-60$ a to grow in $2 \mathrm{M}$ salts without the presence of an osmoprotectant such as glycine-betaine or glucose to restore the osmotic balance.
The mutants $\mathrm{d} 8-60 \mathrm{~b}$ and $\mathrm{d} 8-60 \mathrm{c}$ had very similar porin profiles, a result consistent with the similar growth phenotypes displayed by these mutants. In $2 \mathrm{M}+$ pyruvate conditions, a significant down-regulation of the maltoporin (band 2) and the OmpU-like porin (band 5) but an up-regulation of OmpU (band 3) was observed when compared to the wild-type (Figure 5B). In $2 \mathrm{M}+$ LB nutrient medium, these mutants had reduced levels of the maltoporin (band 2) and the presence of the putative porin (band 4) protein in replacement of the OmpU-like porin (band 5) compared to the wild-type (Figure 5C).

\section{Expression of a single gene cassette in trans maintains normal growth after generation of strains with deleted cassettes}

Since mutant d16-60 (cassettes 16 to 60 deleted) had normal growth phenotypes compared to the wild-type, at least one cassette gene located between cassettes 7 and 16 has a strong pleiotropic affect. All eight cassettes within this region, except cassette 11, encode small hypothetical proteins with homology only to other 


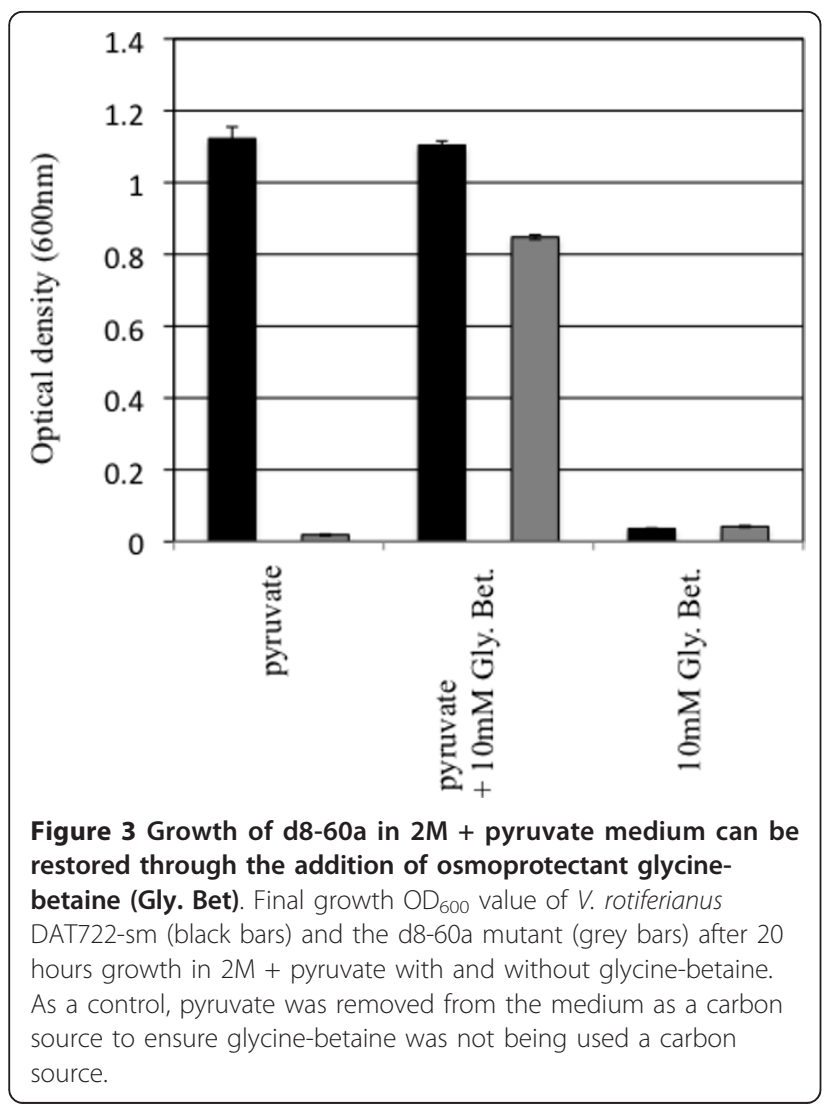

cassette proteins. Therefore, nothing could be inferred regarding their putative function. However, cassette 11 includes a gene, encoding a 257 amino acid protein with pfam http://pfam.sanger.ac.uk/ identifying two domains; 1) an uncharacterized NERD domain at residues 31-150 that has weak homology to nucleases and is commonly associated with other protein domains involved in DNA processing [22], 2) a DNA-binding C4-zinc finger domain at residues $216-257$ found in topoisomerase I proteins and involved in removing excessive negative supercoils from DNA [23]. Based on this bioinformatics analysis one possible biochemical function of the cassette 11 gene product is as a DNA topoisomerase. In addition, experiments with a mutated topoisomerase I (topA) gene have described phenotypes that are similar to those observed in the d8-60 mutants. Most notably, in characterized top $A$ mutants, this includes the requirement for a compensatory mutation, emergence of spontaneous mutants and alterations in the composition of outermembrane porin proteins [23-28].

To test for the cassette 11 gene product being responsible for the phenotype of the mutants described above, the plasmid PMAQ1082 was constructed which comprises only this cassette gene cloned into the vector pJAK16 (Methods). pMAQ1082 was then transformed into the merodiploid strain MD7. MD7 has a complete

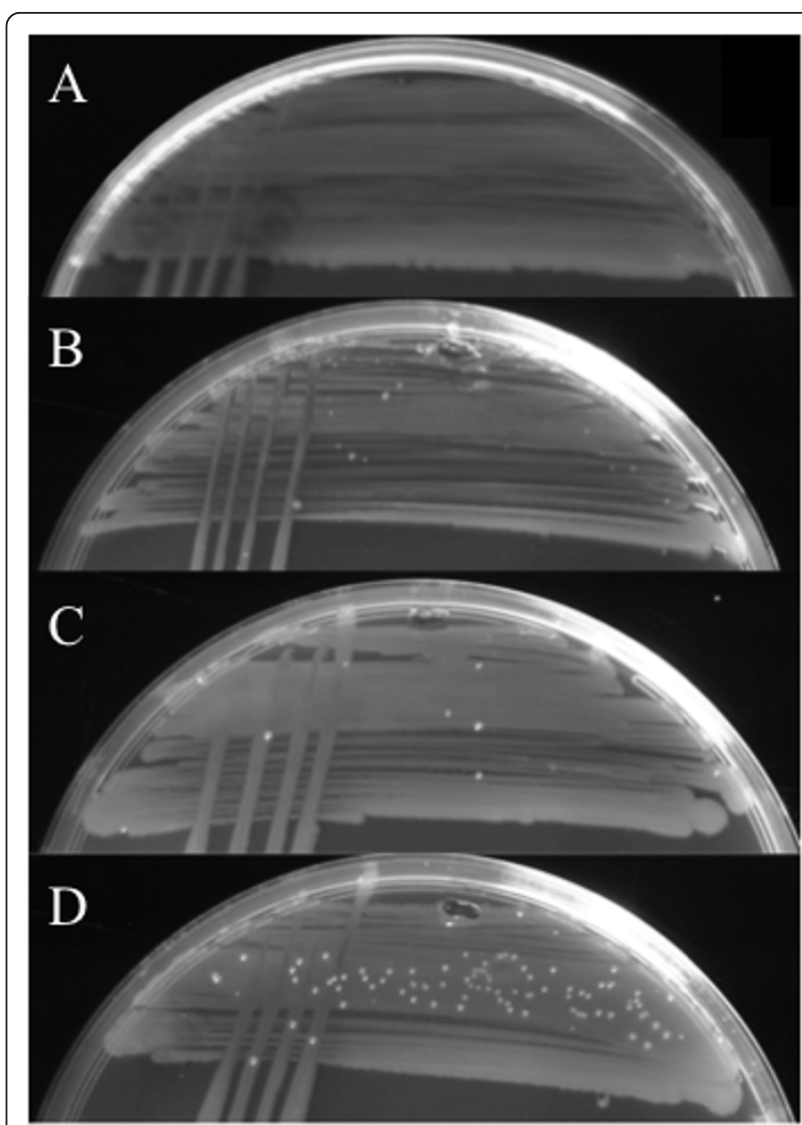

Figure 4 Comparison of $V$. rotiferianus DAT722-Sm (A) and mutants d8-60a (B), d8-60b (C) and d8-60c (D) streaked on LB20 agar. The d8-60 mutants show the presence of microcolonies on the streak line.

DAT722 cassette array and is the strain that was used to create the original deletion mutants (Methods and Figure 1). MD7/pMAQ1082 possesses a phenotype identical to that of DAT722 with respect to porin profiles and growth in LB20 and 2M media. From this strain, a deletion mutant was created, DAT722 $\Delta /$ pMAQ1082 with the same cassettes deleted as strains $\mathrm{d} 8-60 \mathrm{a}$, b and c. The strain DAT722 $\Delta / \mathrm{pMAQ} 1082$ had no major growth defect (Figure 6) and possessed a wild type outermembrane protein profile in all tested media (Figure 5D, E, F). A slight decrease in growth rate was observed in $2 \mathrm{M}+$ pyruvate (Figure 6 ), which may be explained by the up-regulation of a protein (Figure 4F; marked with an asterisk) that is likely due to cassette 11 being removed from its native promoter.

\section{Discussion}

The integron/gene cassette system is broadly dispersed amongst the Proteobacteria and is found in about $10 \%$ of sequenced genomes [2]. In the vibrios it is ubiquitous with arrays generally being especially large. Despite the 


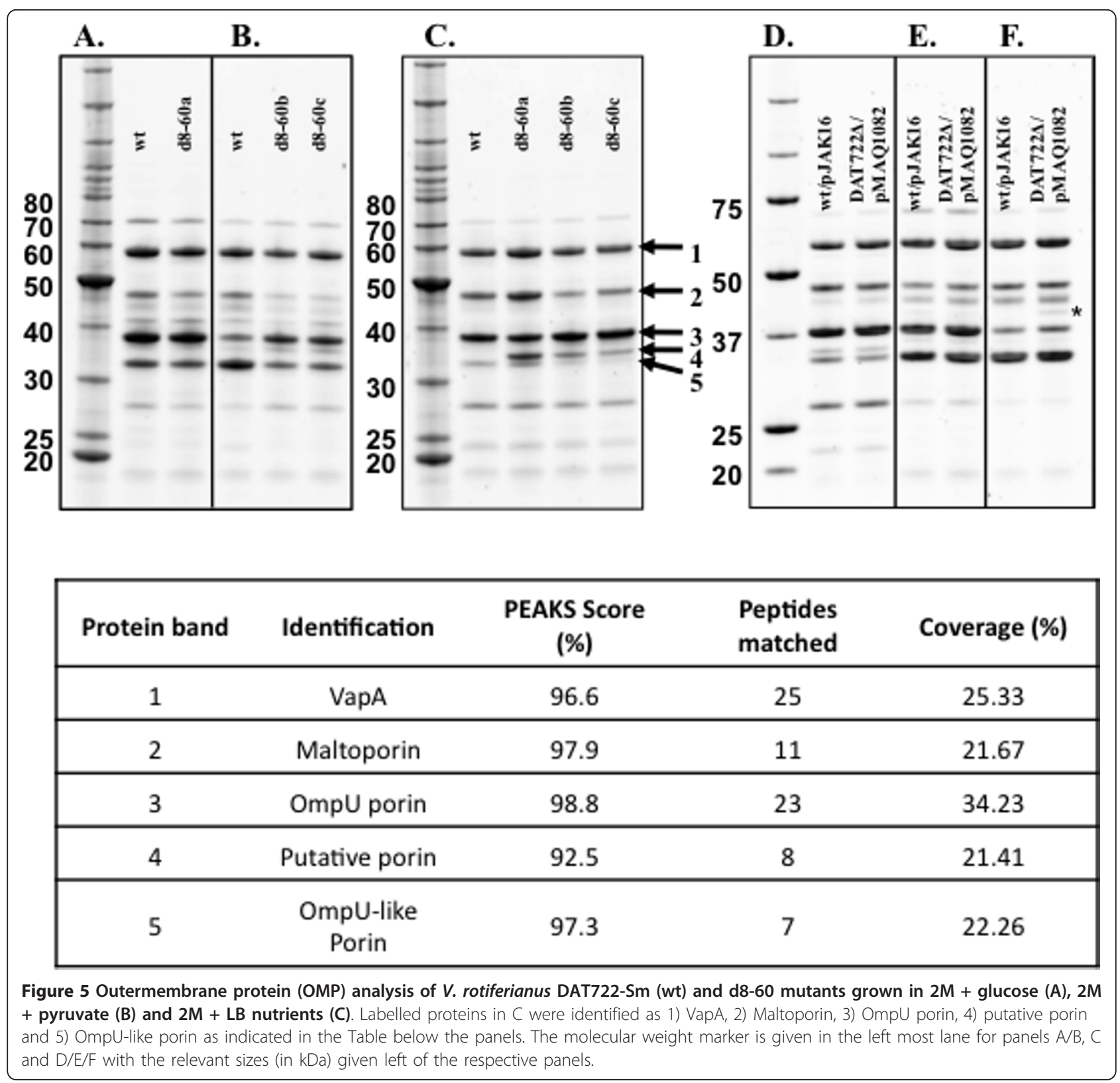

fact that the integron gene cassette "metagenome" pool is very large $[29,30]$, little is known about what the encoded proteins do beyond the enormous contribution some cassette proteins make to the antibiotic resistance problem [31]. A conventional understanding of cell metabolism would suggest they encode accessory phenotypes providing their host with a niche-specific advantage. Antibiotic resistance is a classic example of this since cassettes containing antibiotic resistance genes quite clearly provide a selective advantage in clinical environments where antibiotics are frequently used [31]. These highly mobilized genes frequently cross phylogenetic boundaries and a single gene can protect a cell from toxic compounds irrespective of the metabolic context in which it finds itself. The same phenomenon can extend to some adaptive genes that are part of a "self contained" unit as is the case, for example, in operons on transposons that confer mercury resistance [32].

The vibrios represent a diverse group of marine organisms and members of this group have very large cassette arrays. A typical vibrio cassette array comprises more than 100 novel genes [7]. Moreover, they represent the most dynamic component of the genome. In $V$. cholerae, pandemic strains that are otherwise indistinguishable by most phylogenetic typing techniques can still have very disparate cassette arrays [8]. Similarly, 


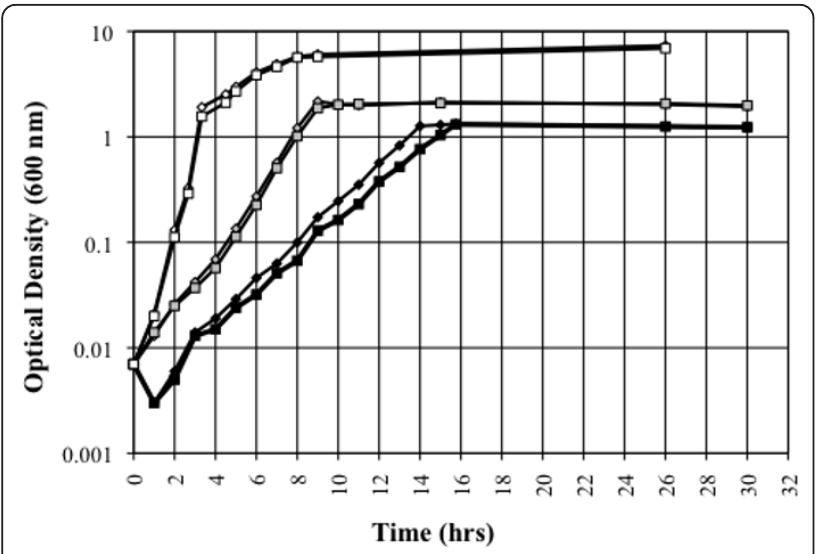

Figure 6 Growth curves of $V$. rotiferianus DAT722-Sm/pJAK16 (squares) and DAT722 $\Delta /$ pMAQ1082 (triangles) in LB20 (white), $2 \mathrm{M}+$ glucose (grey) and $\mathbf{2 M}+$ pyruvate (black). Data presented are representative of results obtained in three independent experiments.

this is true for enclosed symbiotic communities of vibrios [33]. This highly mobile pool of genes, in a metagenomic sense, therefore number in at least the thousands and probably orders of magnitude more [29]. What do all these genes do? Many probably comprise functions that are metabolically independent of the rest of the cell in a manner analogous to antibiotic and heavy metal resistance genes. However, we show for the first time, that at least one mobile gene product can influence other aspects of core cell metabolism. In DAT722 this influence is such that at least one gene within the deleted region is highly adapted to this cell line to the extent that its loss reduces fitness to the point where the host cell is barely viable. The target gene or genes was contained to within a contiguous set of eight cassettes within the DAT722 array. Each of these cassettes contained a single predicted protein (Figure 1 and [11]). All of the predicted proteins are novel in that identical proteins are not present in any other known bacterium. Further, seven of the eight predicted proteins are highly novel to the point where they can only be described as hypothetical proteins. The remaining predicted protein, derived from cassette 11, is also novel although it contains a domain related to the DNA topoisomerase I family of proteins.

Although the precise function of this cassette protein needs to be established experimentally, the data generated was consistent with the hypothesis that the cassette 11 gene product was integrated into an essential cell network in the wild type DAT722. In particular, the fact that supplying this product alone in trans via pMAQ1082 preserved the wild type phenotype after subsequent deletion of cassettes $8-16$ unambiguously points to an essential role in the cell porin regulatory network.

\section{Conclusions}

Overall, this study emphasizes the importance of LGT in bacterial evolution and that this process can bring rapid adaptation not only through acquisition of novel functional genes, but more importantly through gain of genes that alter a cell's regulatory network. Thus, mobile genes can be adaptive over very short time scales such that their loss can threaten the viability of the cell through the disruption of a core metabolic process. This is in contrast to the generally held view that mobile DNA contributes to cell fitness by providing additional protein/s that act largely independently of core cell networks. Also, this data reinforces the point that large integron arrays are not solely dependent on $P_{c}$ for transcription since this cluster of genes if relatively distal to this promoter. It is clear therefore that despite the enormous increase in genomics and proteomic data in recent years, much is still to be learnt about the full of gamut of proteins necessary for important cell metabolic processes.

\section{Methods}

\section{Strains, growth conditions and DNA purification}

Bacterial strains and plasmids used in this study are listed in Table 1. Vibrio strains were routinely grown on Luria-Bertani medium supplemented with $2 \% \mathrm{NaCl}$ (LB20). Escherichia coli strains were routinely grown on Luria-Bertani medium. Growth curves of all vibrio strains were conducted in $100 \mathrm{ml}$ flasks containing 25 $\mathrm{ml}$ of medium. The inoculum was from overnight cultures grown in LB20 and then diluted to $\mathrm{OD}_{600}$ of 0.7 using $2 \% \mathrm{NaCl}$. Growth curve cultures were inoculated at 1:100. In experiments comparing growth of the wildtype and deletion mutants with different carbon sources, a marine minimal salts medium (2M) which mimics a seawater environment [20] was used supplemented with a carbon source (glucose and pyruvate at $11.1 \mathrm{mM}$ and $20 \mathrm{mM}$ respectively). Since growth of the d8-60 mutants in $2 \mathrm{M}$ was dependent on the added carbon source, $2 \mathrm{M}$ supplemented with LB nutrients (10 g tryptone and $5 \mathrm{~g}$ yeast extract per litre) was used to compare the outermembrane protein profiles of all mutants. In vibrio, kanamycin, chloramphenicol and streptomycin were used at $100 \mu \mathrm{g} / \mathrm{ml}, 12.5 \mu \mathrm{g} / \mathrm{ml}$ and $25 \mu \mathrm{g} / \mathrm{ml} \mathrm{respec-}$ tively. In E. coli, kanamycin, chloramphenicol and ampicillin were used at concentrations of $50 \mu \mathrm{g} / \mathrm{ml}, 25 \mu \mathrm{g} / \mathrm{ml}$ and $100 \mu \mathrm{g} / \mathrm{ml}$.

V. rotiferianus DAT722 was isolated from a mud crab aquaculture tank in Darwin (Northern Territory, Australia) [11]. It was typed by multi locus sequence analysis of the recA, pyrH, rpoA, top $A, f t s Z$ and $m r e B$ genes (data not shown). Transformation of $E$. coli XL1-Blue was performed as previously described [34]. Genomic DNA (gDNA) was extracted from overnight cultures 
Table 1 List of strains and plasmids

\begin{tabular}{|c|c|c|}
\hline $\begin{array}{l}\text { Strain or } \\
\text { plasmid }\end{array}$ & Relevant genotype $^{a}$ & $\begin{array}{l}\text { Reference or } \\
\text { source }\end{array}$ \\
\hline \multicolumn{3}{|l|}{ Strains } \\
\hline \multicolumn{3}{|l|}{$\begin{array}{l}\text { V. rotiferianus } \\
\text { DAT722 }\end{array}$} \\
\hline DAT722 & Wild-type & [11] \\
\hline DAT722-Sm & DAT722; Spontaneous Sm ${ }^{R}$ mutant. & This study \\
\hline MD7 & DAT722-Sm; Single recombination cross-over of pVSD2 into cassette $61, \mathrm{Km}^{\mathrm{R}}$ & This study \\
\hline d8-60a & DAT722-Sm; $\Delta$ cassettes 8-60, $\mathrm{Sm}^{\mathrm{R}}, \mathrm{Km}^{\mathrm{R}}$ & This study \\
\hline$d 8-60 b$ & DAT722-Sm; $\Delta$ cassettes 8-60, $\mathrm{Sm}^{\mathrm{R}}, \mathrm{Km}^{\mathrm{R}}$ & This study \\
\hline d8-60b-S & DAT722-Sm; $\Delta$ cassettes 8-60, $\mathrm{Sm}^{\mathrm{R}}, \mathrm{Km}^{\mathrm{R}}$. Spontaneous mutant of d8-60b. & This study \\
\hline d8-60c & DAT722-Sm; $\Delta$ cassettes 8-60, $\mathrm{Sm}^{\mathrm{R}}, \mathrm{Km}^{\mathrm{R}}$ & This study \\
\hline d8-60c-S & DAT722-Sm; $\Delta$ cassettes 8-60, $\mathrm{Sm}^{\mathrm{R}}, \mathrm{Km}^{\mathrm{R}}$. Spontaneous mutant of d8-60c. & This study \\
\hline d16-60 & DAT722-Sm; $\Delta$ cassettes $16-60, \mathrm{Sm}^{\mathrm{R}}, \mathrm{Km}^{\mathrm{R}}$ & This study \\
\hline \multicolumn{3}{|l|}{ E. coli } \\
\hline XL1-Blue & $\mathrm{F}^{\prime}$ proAB lacl' $Z \triangle \mathrm{M} 15$ Tn10/recA1 endA1 gyrA96 thi-1 hsdR17 supE44 relAi, $\mathrm{Tc}^{\mathrm{R}}$ & Stratagene \\
\hline SY327 $\lambda$ pir & $\Delta$ (lac pro) $\arg E($ Am) rif nalA recA56 & [38] \\
\hline $\mathrm{SM} 10 \lambda$ pir & thi thr leu tonA lacY supE recA::RP4-2-Tc::Mu, $T c^{r} \mathrm{Km}^{\mathrm{R}}$ & [39] \\
\hline \multicolumn{3}{|l|}{ Plasmids } \\
\hline pLOW2 & Cloning vector, $\mathrm{Km}^{\mathrm{R}}$ & {$[40]$} \\
\hline pGEM-T Easy & Cloning vector, $A p^{R}$ & Promega \\
\hline pMAQ1080 & $\begin{array}{l}\text { PGEM-T Easy carrying a 1834-bp fragment. The fragment was created using fusion PCR and consists of, in } \\
\text { order, a 448-bp of paralog group } 1 \text { sequence, a 964-bp fragment containing aphA1 and a 410-bp paralog } \\
\text { group } 2 \text { sequence abutted by sall restriction sites. }\end{array}$ & This study \\
\hline pCVD442 & Mobilisable $s a c B$ counter-selectable suicide vector, $A p^{R}$ & [41] \\
\hline $\begin{array}{l}\text { RK600 } \\
\text { pJAK16 } \\
\text { pMAQ1081 } \\
\text { pMAQ1082 }\end{array}$ & $\begin{array}{c}\text { ColE1 oriV; RP4tra RP4 oriT; } \mathrm{Cm}^{\mathrm{R}} \text {; helper plasmid in triparental matings } \\
\text { Low copy IPTG-inducible expression vector, } \mathrm{Cm}^{\mathrm{R}} \\
\text { sall fragment from pMAQ1080 cloned into the unique sall site of pCVD442. } \\
\text { pJAK16 containing cassette } 11\end{array}$ & $\begin{array}{l}\quad[42] \\
{[43]} \\
\text { This study } \\
\text { This study }\end{array}$ \\
\hline
\end{tabular}

${ }^{a} \mathrm{Sm}^{\mathrm{R}}$, streptomycin resistance; $\mathrm{Km}^{\mathrm{R}}$, kanamycin resistance; $\mathrm{Tc}^{\mathrm{R}}$, tetracycline resistance; $\mathrm{Ap}^{\mathrm{R}}$, Ampicillin resistance

using the Purelink genomic DNA mini kit (Invitrogen). Standard PCR was performed using high fidelity platinum Taq (Invitrogen) as per the manufacturer's instructions. Primers (Table 2) were used at a final concentration of $0.5 \mu \mathrm{M}$ each. Plasmid pMAQ1082 was created by amplifying the cassette 11 gene from $V$. rotiferianus DAT722 using primers B-VSD11-F and PVSD11-R (Table 2). The resulting amplicon was directionally cloned in front of the lac promoter using BamHI and PstI. pMAQ1082 was conjugated into MD7 in a triparental conjugation using RK600 as the helper strain.

\section{DAT722 cassette analysis and strain construction}

The cassette array of DAT722 is fully sequenced [12] and consists of 116 gene cassettes although there are 94 different cassette types due to the presence of paralogous cassettes [11]. For the deletion of cassettes by homologous recombination, the presence of paralogous cassettes in different positions of the array was exploited. Two of the paralogous cassette types were selected based on their position in the array. The first paralogous cassette type (group 1) is in positions 6,7 ,
$15,27,49,66,71,76,77$ and 111 . The second paralogous group (group 2) is in positions 34, 61, 83, 87, 90, 93 and 105. Using fusion PCR, a 1834 bp DNA fragment consisting of, in order, a portion of group 1 sequence (448 bp), the aphA1 gene from pLOW2 (964 $\mathrm{bp})$ and a portion of group 2 sequence $(410 \mathrm{bp})$ was amplified and cloned into pGEM-T Easy producing pMAQ1080. The fragment was excised from pMAQ1080 using salI and cloned into the salI site of the $s a c B$-counter selectable suicide vector pCVD442 to create pMAQ1081. Homologous recombination (allele replacement) was used to replace cassettes between group 1 and group 2 cassettes with the 1834 bp fragment created by fusion PCR. Plasmid pMAQ1081 was conjugated into DAT722-Sm using E. coli SM10 as a donor with recombinants selected on LB20 medium supplemented with $100 \mu \mathrm{g} / \mathrm{ml}$ and $25 \mu \mathrm{g} / \mathrm{ml}$ of kanamycin and streptomycin respectively. A merodiploid (designated MD7) was isolated with pMAQ1081 recombining into cassette 61 of the integron cassette array (see Figure 1). An overnight culture of MD7 was inoculated into fresh LB20 at a dilution of $10^{-6}$ and grown until turbidity was evident ( $\sim 6$ hours). For selection of double 
Table 2 Primers used in this study

\begin{tabular}{ccc}
\hline Primer & Sequence (5'-3') & Target \\
\hline PRG1-F & GTC GAC CAA AAT TTG GCT GCT TGT TG & Paralog 1 gene cassettes in Vibrio rotiferianus DAT722 \\
PRG1-R & CAT CAG AGA TTT TGA GAC ACA ACC CGA GCG ACA ATT TTA AGC & Paralog 1 gene cassettes in Vibrio rotiferianus DAT722 \\
PRG5-F & GGC AGA GCA TTA CGC TGA TCA AAG GTC ATA AGT TTT GGT G & Paralog 2 gene cassettes in Vibrio rotiferianus DAT722 \\
PRG5-R & GTC GAC CAT GCG CTA CTT CTA TTT ATG C & Paralog 2 gene cassettes in Vibrio rotiferianus DAT722 \\
Kan-F & GTT GTG TCT CAA AAT CTC TGA TG & aphA1 in pLOW2 (F) \\
Kan-R & TCA GCG TAA TGC TCT GCC & aphA1 in pLOW2 (R) \\
VSD5-F & TGA GCT ACC ACA AGC AAG G & Cassette 5 in Vibrio rotiferianus DAT722 (F) \\
VSD14-F & AAA GCG GTT ACA TTC GGG & Cassette 5 in Vibrio rotiferianus DAT722 (R) \\
VSD25a-F & ACA TAT GTA GAC CCT GTG CG & Cassette 25 in Vibrio rotiferianus DAT722 (F) \\
VSD47-F & CAT TTT AAG TCG GCT CTT CC & Cassette 25 in Vibrio rotiferianus DAT722 (R) \\
VSD62-R & GTA GGT AAT TTC GGC TTC TCG & Cassette 62 in Vibrio rotiferianus DAT722 (R) \\
VSD25b-F & TGC GCA ATA TAT CGC AAG AG & Cassette 25 in Vibrio rotiferianus DAT722 (F) \\
VSD25-R & GCC GTC CAT AGT CGT CAT TT & Cassette 25 in Vibrio rotiferianus sp. DAT722 (R) \\
B-VSD11-F & TT TGG ATC CGA ATA GGG AAA ATC CGT G & Gene from cassette 11 in V. rotiferianus DAT722 (F) \\
P-VSD11-R & TT TCT GCA GT AGT TGA ATT GTT TCA CAG C & Gene from cassette 11 in V. rotiferianus DAT722 (R) \\
\hline
\end{tabular}

cross-over recombinants, a dilution series of the MD7 culture was plated onto LB medium containing $0.4 \%$ $\mathrm{NaCl}, 10 \%$ sucrose and $100 \mu \mathrm{g} / \mathrm{ml}$ kanamycin. Using primers targeting unique cassettes outside the expected deletions (Table 2), colonies were screened for the presence of deletions between $6 / 7$ and 61,15 and 61, 27 and 61 and 49 and 61 . In the case of the mutants $d 8$ 60a, d8-60b, d8-60c, all three generated identical length PCR products by this method indicating identical deletion end points.

\section{Membrane protein analysis}

The outer membrane proteins (OMPs) were extracted as previously described [35] using equal number of cells (equivalent to $5 \mathrm{ml}$ of cells diluted to an $\mathrm{OD}_{600}$ of 5.0). The membrane pellet was resuspended in $200 \mu \mathrm{l}$ of SDS sample buffer containing $5 \mathrm{mM}$ tributylphosphine and $20 \mathrm{mM}$ acrylamide for reduction and alkylation of proteins [36]. The solubilized proteins were diluted 1:5 in SDS sample buffer and $5 \mu$ l subject to polyacrylamide gel electrophoresis using a Criterion XT precast gel (4-12\% Bis-Tris; Bio-Rad). Protein gels were stained with Flamingo protein stain (Bio-Rad) and imaged using a Pharos FX Plus Molecular Imager (Bio-Rad). Flamingo stained protein gels were poststained with colloidal Coomassie G-250 stain and proteins of interest excised for identification by LC-MS/ MS as previously described [37]. PEAKS software (Bioinformatics Solutions Inc.) was used to directly search peptides against a protein sequence FASTA output derived from the $V$. rotiferianus DAT722 genome [12]. The highest PEAKS score (percentage based on a p-value $<0.05$ ) was taken as the closest peptide match. The full sequence of identified proteins is given in the additional file 1.

\section{Additional material}

Additional file 1: lists the full sequence of outermembrane proteins that showed changes in concentration between wild type DAT722 and the mutant d8-60a under particular growth conditions. Proteins were identified via LC-MS/MS analysis as described in the methods.

\section{Acknowledgements}

This work was supported by a grant from the National Health and Medical Research Council of Australia. ML is supported by an ithree Institute Postdoctoral Fellowship.

\section{Author details}

${ }^{1}$ The ithree institute, University of Technology, Sydney. Harris Street and Broadway, Sydney, NSW 2007, Australia. 'Department of Biological Sciences, University of Alberta. 110 St NW Edmonton, Alberta, T6G 2R3, Canada.

\section{Authors' contributions}

$M L$ and HWS designed the research; ML and PR performed the research; ML and YB analyzed data; ML and HWS wrote the paper. All authors have read and approved the final manuscript.

Received: 5 July 2011 Accepted: 18 November 2011 Published: 18 November 2011

\section{References}

1. Hall RM, Brookes DE, Stokes HW: Site-specific insertion of genes into integrons: role of the 59-base element and determination of the recombination cross-over point. Mol Microbiol 1991, 5:1941-1959.

2. Boucher $Y$, Labbate M, Koenig JE, Stokes HW: Integrons: mobilizable platforms that promote genetic diversity in bacteria. Trends in Microbiol 2007, 15:301-309.

3. Labbate M, Case RJ, Stokes HW: The integron/gene cassette system: an active player in bacterial adaptation. In Horizontal gene transfer. Edited by: Gogarten MB, Gogarten JP, Olendzenski LC. Humana Press; 2009:103-125.

4. Thompson FL, lida T, Swings J: Biodiversity of vibrios. Microbiol Mol Biol Rev 2004, 68:403-431.

5. Meibom KL, Blokesch M, Dolganov NA, Wu C-Y, Schoolnik GK: Chitin induces natural competence in Vibrio cholerae. Science 2005, 310:1824-1827.

6. Gulig PA, Tucker MS, Thiaville PC, Joseph JL, Brown RN: USER friendly cloning coupled with chitin-based natural transformation enables rapid mutagenesis of Vibrio vulnificus. Appl Environ Microbiol 2009, 75:4936-4949. 
7. Mazel D: Integrons: agents of bacterial evolution. Nat Rev Microbiol 2006, 4:608-620.

8. Labbate M, Boucher Y, Joss MJ, Michael CA, Gillings MR, Stokes HW: Use of chromosomal integron arrays as a phylogenetic typing system for Vibrio cholerae pandemic strains. Microbiology 2007, 153:1488-1498.

9. Boucher Y, Cordero OX, Takemura A, Hunt DE, Schliep K, Bapteste E, Lopez P, Tarr CL, Polz MF: Local mobile gene pools rapidly cross species boundaries to create endemicity within global Vibrio cholerae populations. MBio 2011, 2(2):e00335-10.

10. Guerin E, Cambray G, Sanchez-Alberola N, Campoy S, Erill I, Da Re S, Gonzales-Zorn B, Barbe J, Ploy M, Mazel D: The SOS response controls integron recombination. Science 2009, 234:1034

11. Boucher $Y$, Nesbo C, Joss M, Robinson A, Mabbutt B, Gillings M, Doolittle WF, Stokes H: Recovery and evolutionary analysis of complete integron gene cassette arrays from Vibrio. BMC Evol Biol 2006, 6(1):3

12. Roy Chowdhury P, Boucher $Y$, Hassan KA, Paulsen IT, Stokes HW, Labbate M: Genome sequence of Vibrio rotiferianus DAT722. J Bacteriol 2011, 192:3381-3382.

13. Michael CA, Labbate M: Gene cassette transcription in a large integronassociated array. BMC Genetics 2010, 11:82.

14. Deshpande CN, Harrop SJ, Boucher Y, Hassan KA, Di Leo R, Xu X, Cui H, Savchenko A, Chang C, Labbate $M$, et al: Crystal structure of an integron gene cassette-associaed protein from Vibrio cholerae identified a cationic drug-binding module. PloS One 2011, 6:e16934.

15. Summers AO: Genetic linkage and horizontal transfer, the roots of the antibiotic multi-resistance problem. Anim Biotechnol 2006, 17:125-135.

16. Barker A, Clark CA: Identification of VCR, a repeated sequence associated with a locus encoding a hemagglutinin in Vibrio cholerae 01. J Bacteriol 1994, 176:5450-5458

17. Barker A, Manning PA: VlpA of Vibrio cholerae 01: the first bacterial member of the alpha 2-microglobulin lipocalin superfamily. Microbiology 1997, 143:1805-1813.

18. Ogawa A, Takeda T: The gene encoding the heat-stable enterotoxin of Vibrio cholerae is flanked by 123 -bp direct repeats. Microbiol Immunol 1993, 37:607-616.

19. Boto L: Horizontal gene transfer in evolution: facts and challenges. Proc $R$ Soc Lond [Biol] 2010, 277:819-827.

20. Paludan-Müller C, Weichart D, McDougald D, Kjelleberg S: Analysis of starvation conditions that allow for prolonged culturability of Vibrio vulnficus at low temperature. Microbiology 1996, 142:1675-1684.

21. Nikaido $\mathrm{H}$ : Molecular basis of bacterial outer membrane permeability revisited. Microbiol Mol Biol Rev 2003, 67:593-656.

22. Grynberg M, Godzik A: NERD: a DNA processing-related domain present in the anthrax virulence plasmid, pXO1. Trends in Biochem Sci 2004, 29:106-110.

23. Tse-Dinh YC, Beran-Steed RK: Escherichia coli DNA topoisomerase I is a zinc metalloprotein with three repetitive zinc-binding domains. J Biol Chem 1988, 263:15857-15859.

24. DiNardo S, Voelkel KA, Sternglanz R: Escherichia coli DNA topoisomerase I mutants have compensatory mutations in DNA gyrase genes. Cell 1982, 31:43-51.

25. Pruss GJ, Manes SH, Drlica K: Escherichia coli DNA topoisomerase I mutants: increased supercoiling is corrected by mutations near gyrase genes. Cell 1982, 31:35-42.

26. Richardson SMH, Higgins CF, Lilley DMJ: The genetic control of DNA supercoling in Salmonella typhimurium. The EMBO J 1984, 3:1745-1752.

27. Graeme-Cook KA, May G, Bremer E, Higgins CF: Osmotic regulation of porin expression: a role for DNA supercoiling. Mol Microbiol 1989, 3:1287-1294.

28. Schofield MA, Agbunag R, Michaels ML, Miller JH: Cloning and sequencing of Escherichia coli mutR shows its identity to top $B$, encoding topoisomerase III. J Bacteriol 1992, 174:5168-5170.

29. Michael CA, Gillings MR, Holmes AJ, Hughes L, Andrew NR, P HM, Stokes HW: Mobile gene cassettes: a fundamental resource for bacterial evolution. Am Nat 2004, 164(1):1-12

30. Koenig JE, Boucher $Y$, Charlebois RL, Nesbo C, Zhaxybayeva O, Bapteste E, Spencer M, Joss MJ, Stokes HW, Doolittle WF: Integron-associated gene cassettes in Halifax Harbour: assessment of a mobile gene pool in marine sediments. Environ Microbio/ 2008, 10:1024-1038.
31. Gillings $M$, Boucher $Y$, Labbate $M$, Holmes A, Krishnan $S$, Holley $M$ Stokes HW: The evolution of class 1 integrons and the rise of antibiotic resistance. J Bacteriol 2008, 190:5095-5100.

32. Mindlin S, Kholodii G, Gorlenko Z, Minakhina S, Minakhina L, Kalyaeva E, Kopteva A, Petrova M, Yurieva O, Nikiforov V: Mercury resistance transposons of Gram-negative environmental bacteria and their classification. Res Microbiol 2001, 152:811-822.

33. Koenig JE, Bourne DG, Curtis B, Dlutek M, Stokes HW, Doolittle WF, Boucher Y: Coral-mucus-associated Vibrio integrons in the Great Barrier Reef: genomic hotspots for environment adaptation. ISME J 2011, 5(6):962-72.

34. Ausubel FA, Brent R, Kingston RF, Moore DD, Seidman JG, Smith JA, Struhl K: Current protocols in molecular biology. New York: John Wiley and Sons; 1998

35. Wang S, Lauritz J, Jass J, Milton DL: A ToxR homolog from Vibrio anguillarum serotype $\mathrm{O} 1$ regulated its own production, bile resistance, and biofilm formation. J Bacterio/ 2002, 184:1630-1639.

36. Herbert B, Galvani M, Hamdan M, Olivieri E, MacCarthy J, Pederson S, Righetti PG: Reduction and alkylation of proteins in preparation of twodimensional map analysis: why, when, and how? Electrophoresis 2001, 22:2046-2057.

37. Jobbins SE, Hill CJ, D'Souza-Basseal JM, Padula MP, Herbert BR, Krockenberger MB: Immunoproteomic approach to elucidating the pathogenesis of cryptococcosis caused by Cryptococcus gattii. J Prot Res 2010, 9:3832-3841.

38. Miller $\mathrm{VL}$, Mekalanos J: Synthesis of cholera toxin is positively regulated at the transcriptional level by toxR. Proc Natl Acad Sci USA 1984, 81:3471-3475.

39. Simon $R$, Priefer $U$, Pühler $A$ : A broad host range mobilization system for in vivo genetic engineering: transposon mutagenesis in gram negative bacteria. Nat Biotech 1983, 1:784-791.

40. Hansen LH, Sørensen SJ, Jensen LB: Chromosomal insertion of the entire Escherichia coli lactose operon, into two strains of Pseudomonas, using a modified mini-Tn5 delivery system. Gene 1997, 186:167-173.

41. Donnenberg MS, Kaper JB: Construction of an eae deletion mutant of enteropathogenic Escherichia coli by using a positive-selection suicide vector. Infect Immun 1991, 59:4310-4317.

42. Kessler B, De Lorenzo V, Timmis KN: A general system to integrate lacZ fusions into the chromosome of gram-negative eubacteria: regulation of the $\mathrm{Pm}$ promoter of the TOL plasmid studies with all controlling elements in monocopy. Mol Gen Genet 1992, 233(1-2):293-301.

43. Thomson VJ, Bhattacharjee MK, Fine DH, Derbyshire KM, Figurski DH: Direct selection of IS903 transposon insertions by use of a broad-host range vector: isolation of catalase-deficient mutants of Actinobacillus actinomycetemcomitans. J Bacteriol 1999, 181:7298-7307.

doi:10.1186/1471-2180-11-253

Cite this article as: Labbate et al:: Integration of a laterally acquired gene into a cell network important for growth in a strain of Vibrio rotiferianus. BMC Microbiology 2011 11:253.

\section{Submit your next manuscript to BioMed Central and take full advantage of:}

- Convenient online submission

- Thorough peer review

- No space constraints or color figure charges

- Immediate publication on acceptance

- Inclusion in PubMed, CAS, Scopus and Google Scholar

- Research which is freely available for redistribution

Submit your manuscript at www.biomedcentral.com/submit
C Biomed Central 